Rejane Reblin de Souza Carvalho ${ }^{1}$ Jordana Herzog Siqueira ${ }^{1}$

\section{Caracterização epidemiológica da esquistossomose no estado do Espírito Santo de 2010 a 2015}

RESUMO| Introdução: A esquistossomose é uma doença parasitária causada por trematódeos do gênero Schistosoma que possui o envolvimento em seu ciclo biológico de caramujos do gênero Biomphalaria e constitui grave problema de saúde pública em alguns estados do Brasil. Objetivo: Objetivou-se analisar o perfil epidemiológico da esquistossomose no estado do Espírito Santo de 2010 a 2015 e direcionar a formulação de políticas públicas a fim de diminuir a incidência dessa doença. Métodos: Foi realizado um estudo descritivo exploratório, utilizando base de dados secundária oriunda do Departamento de Informática do Sistema Único de Saúde (DATASUS). Resultados: A população mais acometida pela doença foram os indivíduos com idade entre 20 e 39 anos, do sexo masculino e que possuem ensino fundamental incompleto. Desses casos identificados, 67,49\% evoluíram para cura. Conclusão: Conclui-se que a falta de medidas socioeducativas e a ausência ou insuficiência de saneamento básico são determinantes para a manutenção dessa morbidade na população. Sendo assim, faz-se necessário o planejamento e a execução de ações de educação em saúde, bem como a implementação de medidas sanitárias para o efetivo controle desse agravo.

Palavras-chave | Schistosoma mansoni; Esquistossomose; Doenças negligenciadas; Parasito. determining factors for the maintenance of this malady in the assessed population; therefore, it is necessary to plan and put in practice health education actions, as well as to implement sanitary measures to effectively control the disease.

Keywords | Schistosoma mansoni; Schistosomiasis; Neglected diseases;

Parasites. 


\section{INTRODUÇÃO|}

A esquistossomose mansônica, popularmente conhecida como "barriga d'água" ou "doença do caramujo", é uma doença infecciosa parasitária causada por trematódeos da espécie Schistosoma mansoni ${ }^{1,2}$. Constitui grave problema de saúde pública em todo o mundo, e seu caráter endêmico está associado à pobreza e ao baixo desenvolvimento econômico. Dessa forma, é uma doença negligenciada com forte determinação social ${ }^{3}$. O aumento do número de casos tem ocorrido em função dos movimentos migratórios e, consequentemente, da falta de saneamento básico (água tratada e rede de esgoto), aliados a fatores culturais de higiene e limpeza que compõem os fatores de risco para a transmissão da doença ${ }^{1,2}$.

O Schistosoma mansoni possui em seu ciclo biológico o envolvimento de caramujos do gênero Biomphalaria, sendo esses os únicos hospedeiros intermediários, e o homem como hospedeiro definitivo. É uma doença que cursa com quadro agudo ou crônico, muitas vezes com poucos sintomas ou de forma assintomática, mas que pode também se manifestar com formas mais graves ${ }^{1,2}$. Por ser uma infecção helmíntica, a esquistossomose está associada a diversos fatores, tais como más condições de tratamento da água, falta de educação em saúde, disseminação dos hospedeiros intermediários e cronicidade 4 .

No Brasil, as pesquisas dessa área tiveram crescimento expressivo a partir de 1950, possivelmente pela expansão da urbanização ${ }^{5}$. Atualmente, há persistência de morbidade e mortalidade por doenças infecciosas e parasitárias, quadro conhecido por polarização epidemiológica ${ }^{6}$, e o ônus econômico da esquistossomose continua alto e resulta em perda de produtividade no Brasil ${ }^{7}$. É uma doença endêmica, com cerca de 43 milhões de pessoas vivendo em áreas de risco de infecção e sete milhões infectadas no país ${ }^{8}$. Então, ressalta-se que apresenta ampla distribuição no país e continua a se configurar como uma das doenças parasitárias de maior importância em saúde pública no Brasil ${ }^{4}$. É importante destacar que as áreas litorâneas e de mata de alguns estados nordestinos, como Alagoas, Maranhão, Pernambuco, Sergipe e Bahia, além de Minas Gerais, constituem-se como a região de maior endemicidade para a doença ${ }^{1,9}$.

A esquistossomose se espalhou de forma ampla no país devido aos movimentos migratórios, e seu alastramento foi auxiliado pela longevidade dos parasitos adultos, que têm vida média de cinco anos, podendo chegar a várias décadas.
Fatores adicionais são a grande capacidade de reprodução das fêmeas, com uma média de quatrocentos ovos por dia, a existência de indivíduos infectados, que mesmo quando longe dos focos de transmissão são capazes de permanecer excretando ovos por mais de vinte anos, o caráter crônico e insidioso da doença, permitindo que durante muito tempo o paciente não busque tratamento, e a ampla distribuição dos hospedeiros intermediários ${ }^{8}$.

No Brasil, entre 2010 e 2012, ocorreram 941 internações por 100 mil habitantes e 1.464 óbitos por esquistossome ${ }^{8}$. A prevalência da doença no Espírito Santo em 2010 foi 3,5\% em 49.476 pessoas examinadas (3,9 casos para cada 10.000 habitantes), e a média anual de internação, no período de 2005 a 2010, foi de oito ocorrências. Também foi observada, no Estado, redução da taxa de internação por 100 mil habitantes, de 0,29, em 2005, para 0,23, em 2010. Ocorreram 12 óbitos nesse mesmo período, com aumento na taxa de mortalidade por 100 mil habitantes de 0,23, em 2005, para 0,37 , em $2010^{10}$. A transmissão é endêmica em 47 dos 78 municípios existentes no Estado, sendo as regiões com maior incidência as Zonas Serranas do Centro, Baixo Guandu, Vale do Rio Doce e Zona Serrana do Sul ${ }^{10}$. Também é válido destacar que os municípios fronteiriços com as regiões endêmicas do estado de Minas Gerais são bastante vulneráveis à doença ${ }^{10}$.

Mediante o exposto, objetivou-se analisar o perfil epidemiológico da esquistossomose no estado do Espírito Santo, no período de 2010 a 2015, para identificar o perfil de acometidos e direcionar a formulação de políticas públicas.

\section{MÉTODOS |}

Realizou-se um estudo do tipo descritivo exploratório com o intuito de avaliar o perfil epidemiológico da esquistossomose no estado do Espírito Santo, no período de 2010 a 2015. O referido estado está situado na região Sudeste do Brasil e apresentava uma população total, no período do estudo, de 3.514.952 habitantes, dentre os quais 421.919 apresentaram o primeiro sintoma da doença nos anos em que o estudo foi realizado.

A população do estudo foi constituída por todos os casos de esquistossomose confirmados em residentes no estado do Espírito Santo, registrados no banco de dados do Departamento de Informática do Sistema Único de Saúde 
do Brasil (DATASUS), no período de 2010 a 2015. Dessa forma, foram utilizados dados secundários oriundos das bases de dados do DATASUS, conforme a $10^{a}$ Classificação Internacional de Doenças (CID-10).

As estimativas de população por sexo, idade e escolaridade foram obtidas de acordo com o Instituto Brasileiro de Geografia e Estatística (IBGE). Na análise dos dados, inicialmente foi realizada a vinculação manual das informações registradas no DATASUS com o objetivo de verificar a uniformidade dos registros de casos de esquistossomose. A coleta de dados ocorreu no período de janeiro e fevereiro de 2018.

Foram utilizadas as seguintes variáveis: 1) municípios com maior incidência; 2) faixa etária; 3) casos autóctones; 4) evolução do caso; 5) escolaridade; 6) sexo; 7) carga parasitária. Como critérios de exclusão, estabeleceu-se o fato de não ser residente no estado do Espírito Santo e não se adequar à definição de caso utilizada de acordo com as diretrizes técnicas para vigilância da esquistossomose?

Para a caracterização epidemiológica, foram calculadas as frequências simples (absoluta e relativa). $\mathrm{Na}$ identificação da taxa de prevalência, utilizou-se, no numerador, os casos confirmados de esquistossomose em residentes do Espírito Santo referentes ao período de 2010 a 2015, registrados no DATASUS, e, no denominador, a população total do Estado, informada pelo IBGE no ano de $2010^{11}$.

Este estudo obedece aos princípios éticos da Resolução 466/2012 do Conselho Nacional de Saúde. Os dados utilizados foram acessados em bancos de dados oficiais e de acesso livre, o que justifica a ausência de parecer de Comitê de Ética em Pesquisa.

\section{RESULTADOS |}

Entre 2010 e 2015, a população examinada foi de 421.919 no estado do Espírito Santo, e destes, 8.007 apresentaram resultado positivo para a helmintíase e 3.470 foram casos confirmados notificados.

$\mathrm{Na}$ Figura 1, observa-se que indivíduos do sexo masculino foram os mais acometidos pela doença, representando $64,25 \%$ do total de casos confirmados e notificados.

Figura 1 - Número de casos confirmados e notificados de esquistossomose segundo sexo, por ano de diagnóstico, Espírito Santo, 2010 a 2015

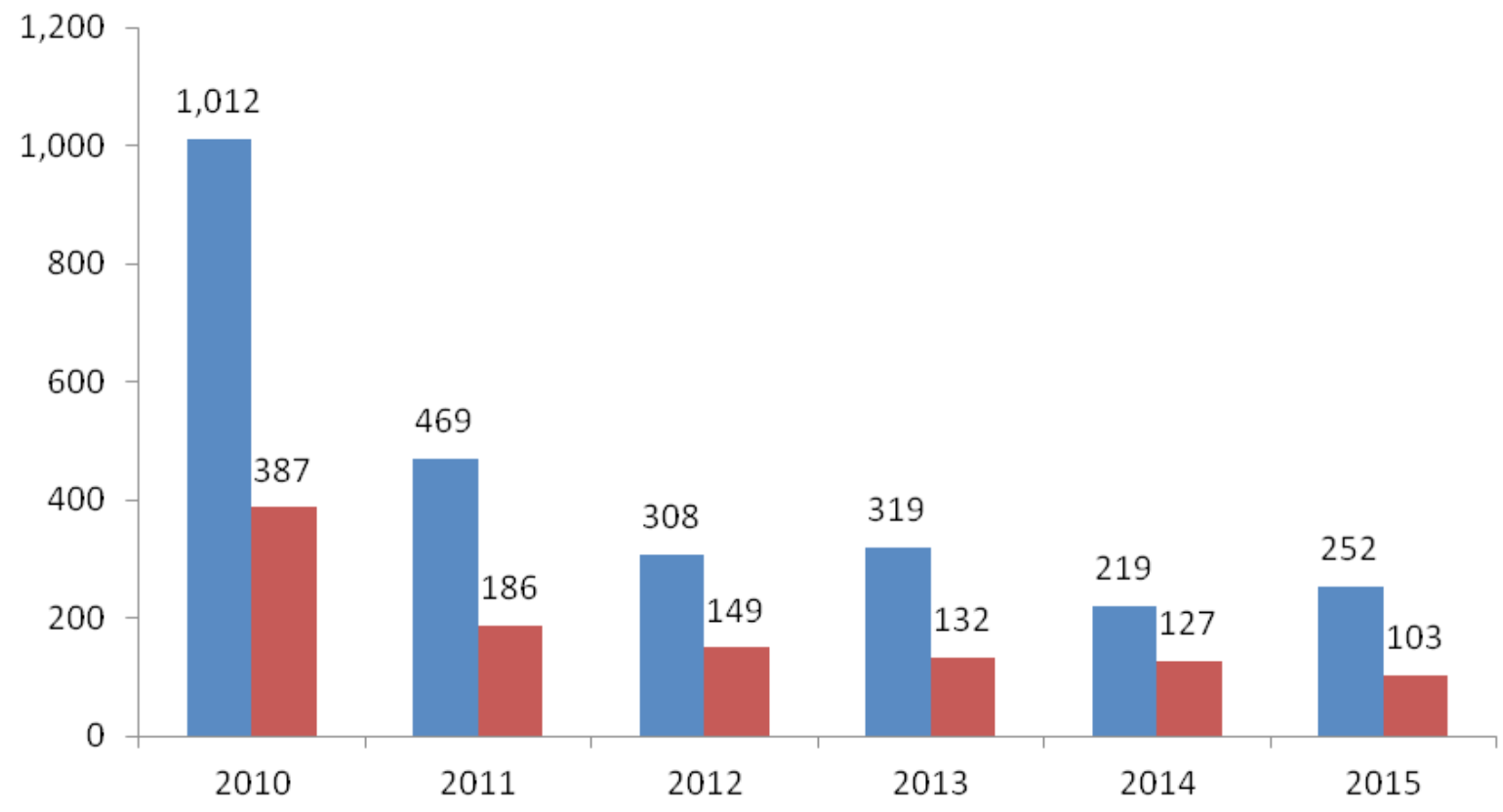

Masculino

Feminino

Fonte: Tabnet, DATASUS. 
Figura 2 - Casos positivos e carga parasitária em individuos diagnosticados com esquistossomose entre 2010 e 2015 no Estado do Espirito Santo

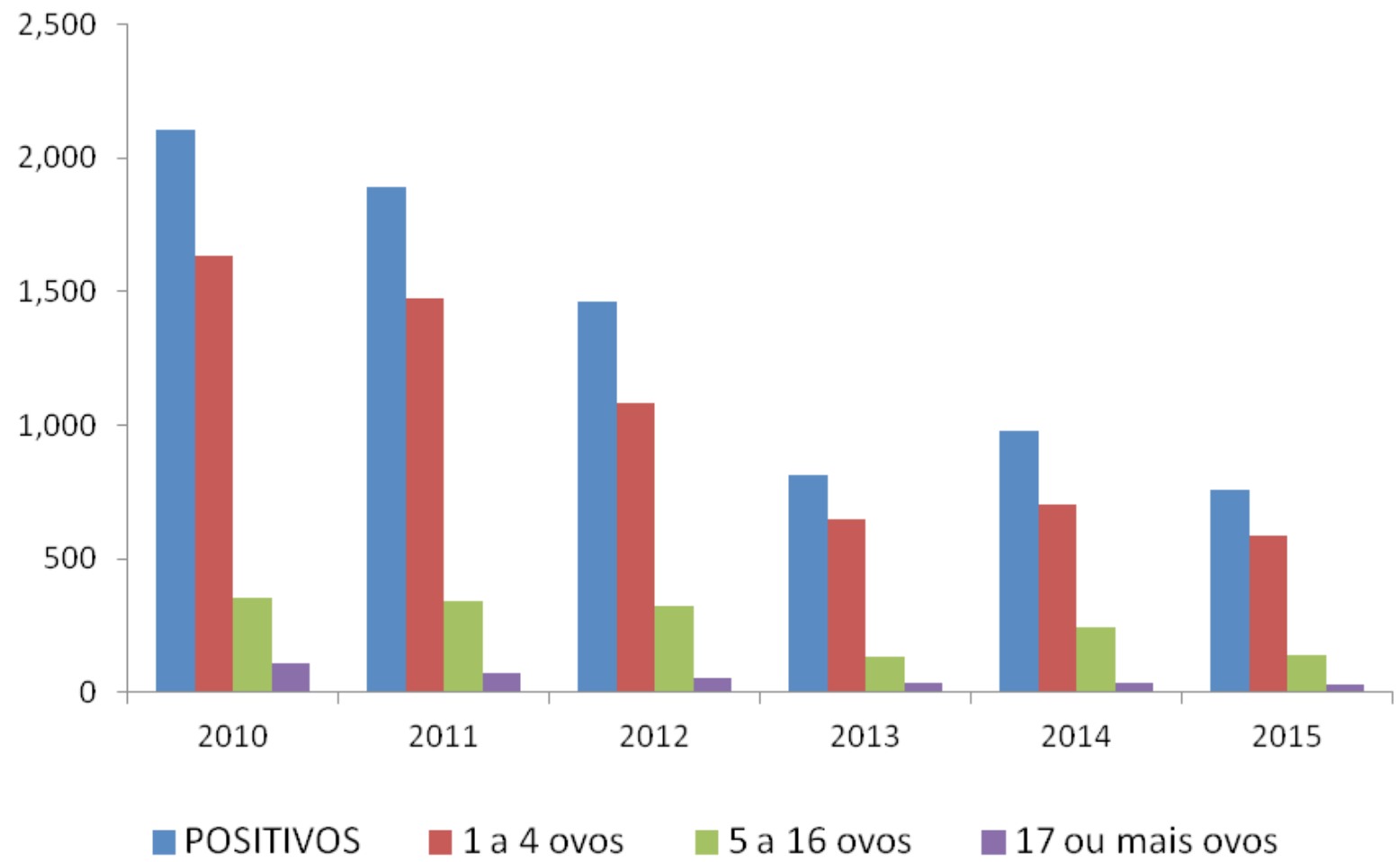

Fonte: Tabnet, DATASUS.

Destaca-se, na Figura 2, a carga parasitária descrita no Programa de Controle da Esquistossomose (PCE) ${ }^{8}$ referente aos casos positivos e às quantidades de ovos encontradas nas amostras observadas. De acordo com a fonte de dados pesquisada, foi observado que apenas uma das espécies de caramujo apresentou positividade no Estado. Foram capturados 504 caramujos da espécie Biomphalaria tenagophila e todos foram positivos. As outras espécies capturadas (Biomphalaria glabrata e Biomphalaria straminea) não apresentaram positividade.

De acordo com o $\mathrm{PCE}^{8}$, presente na base de dados do DATASUS, as cidades que apresentaram maior número de casos investigados foram: Afonso Cláudio (52.948), Colatina (43.802), Pancas (30.530), Barra de São Francisco (23.993), Alto Rio Novo (21.468), Iuna (21.348) e Santa Maria de Jetibá (20.906). Esses municípios concentraram 95\% dos casos ocorridos no Estado. A taxa de prevalência da doença no período do estudo apresentou uma tendência decrescente entre os anos de 2010 e 2015, diminuindo 63,34\% (de 3,9 para 1,0 caso para cada 10.000 habitantes), conforme observado na Figura 3.
Na Tabela 1, estão apresentados os dados referentes aos casos notificados de esquistossomose no período de estudo. Verificou-se que a população mais acometida está na faixa etária de 20 a 39 anos e entre os que cursaram até a faixa entre a $5^{\mathrm{a}}$ e a $8^{\mathrm{a}}$ séries incompletas. Desses casos, 67,5\% evoluíram para cura após tratamento, e 59,88\% eram casos autóctones.

\section{DISCUSSÃO|}

O estudo permitiu conhecer o perfil dos indivíduos acometidos por esquistossomose. Foi possível identificar que os indivíduos mais acometidos pela doença apresentam ensino fundamental incompleto, estão na faixa etária de 20 a 39 anos e são do sexo masculino. Na maioria dos exames avaliados, a carga parasitária encontrada foi de um a quatro ovos, com evolução para cura do agravo. Além disso, pode-se notar uma diminuição na prevalência da doença no Estado. 
Figura 3 - Número de casos e taxa de prevalência de esquistossomose por ano de diagnóstico, Espírito Santo, 2010-2015

\section{Número de casos}

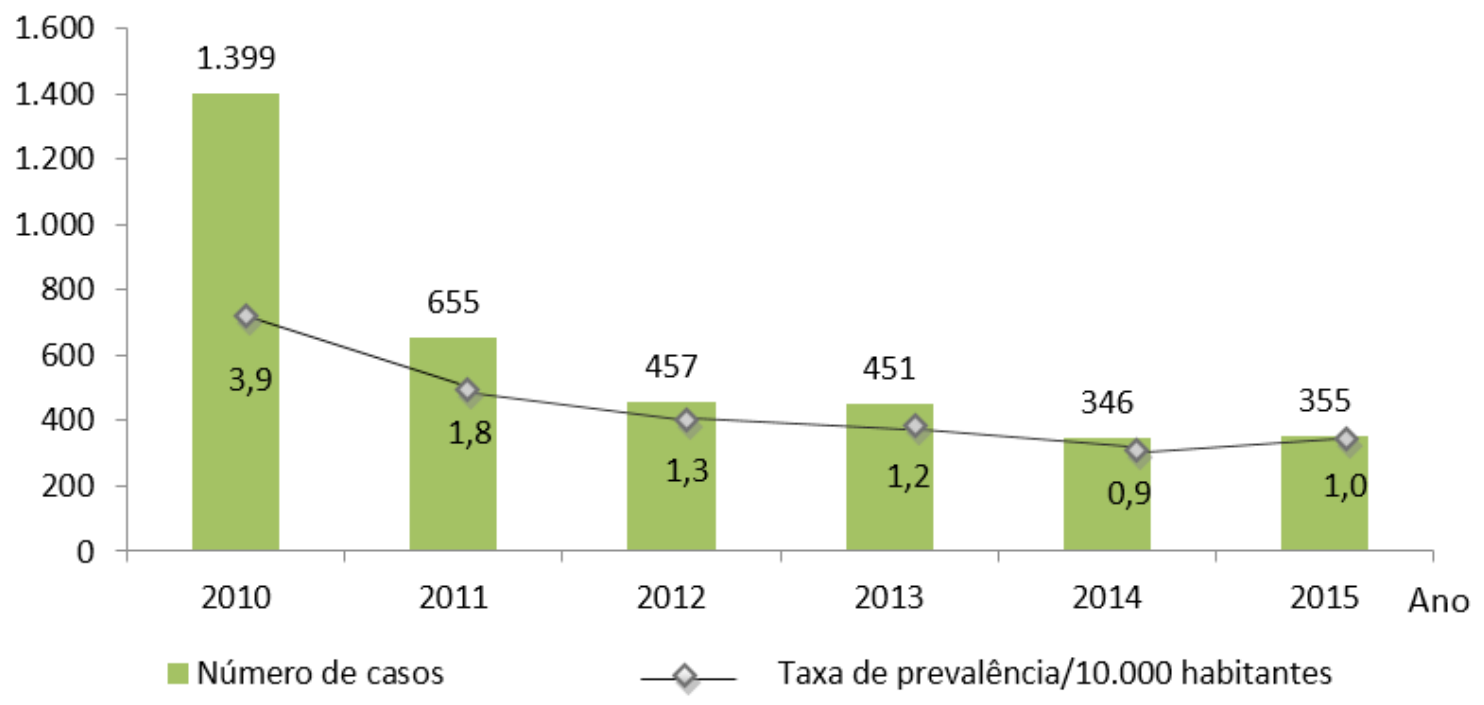

Fonte: Tabnet, DATASUS.

Tabela 1 - Número de casos confirmados e notificados de esquistossomose segundo faixa etária, casos autóctones por município de residência, evolução do caso e escolaridade por ano de diagnóstico, Espirito Santo, 2010 a 2015

\begin{tabular}{|c|c|c|c|c|c|c|c|}
\hline & 2010 & 2011 & 2012 & 2013 & 2014 & 2015 & Total \\
\hline \multicolumn{8}{|l|}{ Faixa etária } \\
\hline$<1$ ano & 18 & 8 & 4 & 3 & 2 & 0 & 35 \\
\hline 1-4 anos & 13 & 3 & 2 & 8 & 4 & 1 & 31 \\
\hline 5-9 anos & 46 & 17 & 18 & 14 & 9 & 6 & 110 \\
\hline 10-14 anos & 136 & 43 & 45 & 28 & 24 & 10 & 286 \\
\hline 15-19 anos & 132 & 47 & 43 & 30 & 24 & 11 & 287 \\
\hline 20-39 anos & 574 & 285 & 195 & 215 & 152 & 86 & 1.507 \\
\hline 40-59 anos & 373 & 189 & 128 & 119 & 103 & 47 & 959 \\
\hline $60-64$ anos & 54 & 23 & 11 & 11 & 13 & 3 & 115 \\
\hline 65-69 anos & 29 & 22 & 6 & 10 & 5 & 5 & 77 \\
\hline 70 e + & 22 & 17 & 5 & 11 & 2 & 5 & 62 \\
\hline \multicolumn{8}{|l|}{ Casos autóctones } \\
\hline Indeterminado/Branco & 143 & 63 & 55 & 41 & 51 & 38 & 391 \\
\hline Sim & 1.024 & 386 & 238 & 195 & 153 & 82 & 2.078 \\
\hline Não & 231 & 205 & 164 & 213 & 134 & 54 & 1.001 \\
\hline \multicolumn{8}{|l|}{ Evolução do caso } \\
\hline Ignorado/Branco & 475 & 142 & 99 & 125 & 101 & 100 & 1.042 \\
\hline Cura & 899 & 477 & 342 & 315 & 235 & 74 & 2.342 \\
\hline Não cura & 22 & 32 & 13 & 7 & 2 & 0 & 76 \\
\hline Óbitos por Esquistossomose & 2 & 3 & 1 & 2 & 0 & 0 & 8 \\
\hline Óbitos por outras causas & 0 & 0 & 2 & 0 & 0 & 0 & 2 \\
\hline
\end{tabular}


*continuação.

\begin{tabular}{|c|c|c|c|c|c|c|c|}
\hline \multicolumn{8}{|l|}{ Escolaridade } \\
\hline Ignorado/Branco/ não se aplica & 194 & 150 & 106 & 149 & 144 & 224 & 204 \\
\hline Analfabeto & 65 & 21 & 12 & 11 & 10 & 4 & 123 \\
\hline $1^{\mathrm{a}}$ a $4^{\mathrm{a}}$ série incompleta & 304 & 156 & 84 & 75 & 58 & 28 & 705 \\
\hline $4^{\mathrm{a}}$ série completa & 108 & 49 & 38 & 35 & 27 & 9 & 266 \\
\hline $5^{\mathrm{a}}$ a $8^{\mathrm{a}}$ série incompleta & 272 & 107 & 97 & 87 & 52 & 30 & 645 \\
\hline Ensino fundamental completo & 65 & 36 & 31 & 33 & 20 & 5 & 190 \\
\hline Ensino médio incompleto & 70 & 27 & 19 & 31 & 35 & 13 & 195 \\
\hline Ensino médio completo & 123 & 60 & 53 & 59 & 38 & 26 & 359 \\
\hline Educação superior & 27 & 13 & 13 & 13 & 14 & 2 & 82 \\
\hline
\end{tabular}

Fonte: Tabnet, DATASUS.

Importante destacar que o maior número de ações educativas realizadas pela atenção primária e vigilância em saúde, a maior conscientização da população em relação ao agravo e a falha na realização das notificações da doença, visto que é um agravo de notificação compulsória ${ }^{12-14}$, podem estar associados à diminuição da prevalência da doença no Estado.

A presença de indivíduos com esquistossomose associada à presença de caramujo em algumas regiões é elemento indicativo de situação de endemia. Tal situação serve de alerta para medidas de controle contra a disseminação da doença ${ }^{1}$. Em relação à prevalência, a esquistossomose é classificada da seguinte forma: baixa endemicidade para a prevalência inferior a 5\%, média endemicidade para prevalência superior a $5 \%$ e inferior a $15 \%$ e alta endemicidade para prevalência superior a 15\%. Portanto, a região estudada é considerada de média endemicidade ${ }^{15}$ quando comparada a outros estados do país,16-17. Essa prevalência pode ser atribuída a fatores como habitat, maior contato com água contaminada e maior exposição aos moluscos ${ }^{18}$.

A carga parasitária encontrada nos indivíduos é importante para identificar e confirmar o diagnóstico. Além disso, os sintomas que podem aparecer são indicativos da possibilidade de uma grande ou pequena carga, direcionando o tratamento de acordo com a agressividade da doença. É importante ressaltar que outros estudos realizados no estado da Bahia e Alagoas ${ }^{1,12-13}$ corroboram o resultado encontrado no presente estudo, estando o maior número de casos positivos com carga parasitária que variava de um a quatro ovos.
Pacientes com baixa carga parasitária, como aqueles identificados em maior número no estudo, podem ser responsáveis pela manutenção do foco da doença. Sintomas intestinais, como diarreia e pequenos sangramentos, são comuns em pacientes com carga parasitária baixa, enquanto os sintomas mais graves, como hepatoesplenomegalia, comprometimento renal, comprometimento neurológico, comprometimento pulmonar, comprometimento cardíaco ou de outros órgãos, são indicativos de alta carga parasitária $^{14}$.

Identificou-se que a prevalência da doença no estado do Espírito Santo, nos anos de 2010 a 2015, apresentou tendência negativa, variando de 1 a 3,9 casos por 10.000 habitantes, e também que os indivíduos adquiriram a doença no próprio município de residência, com idade entre 20 e 39 anos, sendo a maioria do sexo masculino e com ensino fundamental incompleto. Desses casos identificados, 67,49\% evoluíram para cura, e 30\% tiveram classificação ignorada para evolução. O perfil de faixa etária e evolução do tratamento encontrados no presente estudo também podem ser observados no estudo de Silva e Souza $^{12}$, realizado em um município do sertão baiano em 2015. Estudo realizado em Minas Gerais no ano de 2007 evidenciou prevalência de $2,5 \%$ na população estudada e associação da doença com as faixas etárias de 15 a 19 e 20 a 29 anos e com o tipo de trabalho, uma vez que trabalhadores rurais apresentavam mais probabilidade de infecção do que outros trabalhadores, não tendo sido notificados casos graves da doença ${ }^{19}$. No estado de Alagoas, no período de 2010 a 2014, a prevalência da doença variou de 7,40\% a $6,22 \%$. As notificações da doença foram predominantes do sexo masculino, sobretudo na faixa etária entre 15 e 49 anos $^{1}$. 
A maior prevalência da doença no sexo masculino também foi identificada por trabalhos realizados no Rio de Janeiro e na Bahia ${ }^{1,20,21}$, bem como em um estudo realizado em Pernambuco, o qual evidenciou a internação hospitalar por esquistossomose maior em homens e em todas as faixas etárias ${ }^{22}$. Isso pode se justificar pela maior prática de atividades de lazer e pesca em relação ao sexo feminino. Além disso, a atividade em área rural e as condições socioeconômicas favorecem o acometimento dessa população, já que o modo de produção agrícola e as condições ambientais foram, ao longo do tempo, moldando as práticas coletivas para otimização da produtividade. Dessa forma, acabaram por se transformar em fatores de risco adicionais para a transmissão da esquistossomose, visto que alguns sistemas de irrigação adotados levam caramujos e cercárias para dentro das hortas, e a lavagem das verduras nos rios condicionam os agricultores a uma exposição contínua ${ }^{23,24}$.

Em relação ao país, a prevalência média desse agravo, de 1990 a 2010, foi de 8\%, mas a distribuição espacial em áreas endêmicas não é homogênea, como já relatado anteriormente ${ }^{25}$. Recente revisão sistemática e metanálise $e^{26}$ abordou os fatores associados à infecção pelo Schistosoma mansoni no Brasil de 2000 a 2016, estando em acordo com o perfil de indivíduos do presente estudo. As maiores prevalências da doença foram encontradas em homens de 10 a 30 anos, e fatores como escolaridade, ocupação do chefe de família, renda familiar, número de pessoas por cômodo no domicílio e descarte de resíduos também foram preditores significativos de esquistossomose ${ }^{26}$.

Embora exista tratamento eficiente para a doença, seu controle é complexo, pois exige a sinergia de diferentes serviços, como o saneamento básico e a educação. Os programas de controle da esquistossomose no Brasil têm contribuído tanto para reduzir a prevalência quanto as formas graves da doença, mas não têm impedido que novos focos apareçam, principalmente nas áreas periféricas dos grandes centros urbanos, principalmente pela desigualdade social e pela migração interna ${ }^{1,26}$. Iniciativa interessante foi realizada em um município de Minas Gerais com alta prevalência da doença $(70 \%)$, em que foi estabelecido um programa de educação a professores e estudantes para investigar as suas percepções da realidade, dos ambientes e da doença e promover mudança de postura ${ }^{27}$. Outra iniciativa recente foi a implantação do Programa SANAR (Plano para Redução e Eliminação de Doenças Negligenciadas) em Pernambuco, que envolveu educação comunitária e avaliação ambiental, e apresentou resultados satisfatórios na redução da ocorrência de esquistossomose em áreas hiperendêmicas ${ }^{28}$.

O estudo apresenta algumas limitações, visto que utilizou informações retiradas da base de dados do DATASUS, podendo ter ocorrido subnotificação de alguns casos e erros de registro. Contudo, é uma base de dados oficial e de preenchimento obrigatório nos serviços de saúde. Portanto, conclui-se que os objetivos puderam ser alcançados.

\section{CONCLUSÃO|}

Este estudo permitiu avaliar o perfil dos indivíduos mais acometidos pela esquistossomose e refletir sobre a importância do conhecimento acerca da dinâmica dessa doença no estado do Espírito Santo. Deste modo, identificar grupos que apresentam elevado risco da infecção constitui uma tarefa de extrema relevância. Espera-se que esses achados possam estimular a utilização de condutas preventivas e melhor planejamento das ações de saúde.

O estudo pode contribuir para a reflexão das práticas e políticas públicas relacionadas à esquistossomose no Estado, visto que, para o controle efetivo dos casos, além das medidas imediatas de cura e controle, são necessárias ações de prevenção, como melhorias nas condições de vida das coletividades, educação sanitária e vigilância dos vetores e fatores condicionantes para a sua transmissão e expansão.

Para finalizar, vale mencionar que são necessárias mais discussões acerca da melhoria na qualidade dos registros dos sistemas de informação em saúde para que as informações geradas sejam adequadas para propiciar ações de vigilância e controle. No entanto, a utilização de dados do DATASUS já constitui instrumento importante para o conhecimento da ocorrência dessa enfermidade no estado do Espírito Santo.

\section{REFERÊNCIAS |}

1. Rocha TJM, Santos MCS, Lima MVM, Calheiros CML, Wanderley FS. Aspectos epidemiológicos e distribuição dos casos de infecção pelo Schistosoma Mansoni em municípios do Estado de Alagoas, Brasil. Rev Pan-Amaz Saude. 2016; $7(2): 27-32$. 
2. Gomes ACL, Galindo JM, Lima NN, Silva EVG. Prevalência e carga parasitária da esquistossomose mansônica antes e depois do tratamento coletivo em Jaboatão dos Guararapes, Pernambuco. Epidemiol Serv Saúde. 2016; 25(2):243-50.

3. Oliveira ECA, Pimentel TJF, Araujo JPM, Oliveira LCS, Fernando VCN, Loyo RM, et al. Investigação sobre os casos e óbitos por esquistossomose na cidade do Recife, Pernambuco, Brasil, 2005-2013. Epidemiol Serv Saúde. 2018; 27(4):e2017190.

4.Tibiriçá SHC, Guimarães FB, Teixeira MTB. A esquistossomose mansoni no contexto da política de saúde brasileira. Ciênc Saúde Coletiva. 2011; 16(1):1375-81.

5. Andrade ZA. A esquistossomose no Brasil após quase um século de pesquisas. Rev Soc Bras Med Trop. 2002; 35(5):509-13.

6. Araújo JD. Polarização epidemiológica no Brasil. Epidemiol Serv Saúde. 2012; 21(4):533-8.

7. Nascimento GL, Pegado HM, Domingues ALC, Ximenes RAA, Itria A, Cruz LN, et al. The cost of a disease targeted for elimination in Brazil: the case of schistosomiasis mansoni. Mem Inst Oswaldo Cruz. 2019; 114:e180347.

8. Brasil. Ministério da Saúde. Secretaria de Vigilância em Saúde. Vigilância da esquistossomose mansoni: diretrizes técnicas. 4. ed. Brasília: Ministério da Saúde; 2014.

9. Brasília. Ministério da Saúde. DATASUS. Programa de controle da esquistossomose no Espírito Santo. Brasília: Ministério da Saúde; 2018.

10. Ministério da Saúde. Secretaria de Vigilância em Saúde. Sistema nacional de vigilância em saúde: relatório de situação do Espírito Santo. Brasília: Ministério da Saúde; 2011.

11. Instituto Brasileiro de Geografia Estatística. População residente no Estado do Espírito Santo. Rio de Janeiro: IBGE; 2010.

12. Silva GC, Souza AP. Perfil epidemiológico de parasitoses intestinais em um município do sertão baiano. Saúde em Redes. 2017; 3(3):214-21.
13. Borges LS, Souza TS, Motta RL, Azevedo BD, Dias JAA, Nery IG. Perfil epidemiológico da esquistossomose em comunidade periférica do município de Jequié-BA. Rev Univ Vale do Rio Verde. 2014; 12(2):812-20.

14. Jordão MCC, Macedo VKB, Lima AF, Xavier Junior AFS. Caracterização do perfil epidemiológico da esquistossomose no estado de Alagoas. Ciên Biol Saúde. 2014; 2(2):175-88.

15. Melo AGS, Melo CM, Oliveira CCC, Oliveira DS, Santos VB, Jeraldo VLS, et al. Esquistossomose em área de transição rural-urbana: reflexões epidemiológicas. Ciênc Cuid Saude. 2011; 10(3):506-13.

16. Silva PCV, Domingues ALC. Aspectos epidemiológicos da esquistossomose hepatoesplênica no Estado de Pernambuco, Brasil. Rev Epidemiol Serv Saúde. 2011; 20(3):327-36.

17. Martins Junior DV, Barreto ML. Aspectos macroepidemiológicos da esquistossomose mansônica: análise da relação da irrigação no perfil espacial da endemia no Estado da Bahia, Brasil. Cad Saúde Pública. 2003; 19(2):383-93.

18. Lima KM, Teles RBA, Castro CMMB. Esquistossomose mansônica e translocação bacteriana: existe associação? RBAC. 2016; 48(2):110-17.

19. Vasconcelos CH, Cardoso PCM, Quirino WC, Massara CL, Amaral GL, Cordeiro R, et al. Avaliação de medidas de controle da esquistossomose mansoni no Município de Sabará, Minas Gerais, Brasil, 1980-2007. Cad Saúde Pública. 2009; 25(5):997-1006.

20. Nunes FC, Costa MCE, Filhote MIF, Sharapinn M. Perfil epidemiológico da Esquistossomose mansoni no bairro Alto da Boa Vista. Cad Saúde Col. 2005; 13(3):60516.

21. Guimarães ICS, Tavares Neto J. Transmissão urbana da esquistossomose em crianças de um bairro de Salvador, Bahia. Rev Soc Bras Med Trop. 2006; 39(5):451-55.

22. Resendes APC, Santos RS, Barbosa CS. Internação hospitalar e mortalidade por esquistossomose mansônica no Estado de Pernambuco, Brasil, 1992/2000. Cad Saúde Pública. 2005; 21(5):1392-401. 
23. Barbosa CS, Barbosa FS. Padrão epidemiológico da esquistossomose em comunidade de pequenos produtores rurais de Pernambuco, Brasil. Cad Saúde Pública. 1998; 14(1):129-37.

24. Ministério da Saúde. Guia de vigilância epidemiológica. Brasília: Ministério da Saúde; 2005.

25. Brasil. Ministério da Saúde. Plano integrado de ações estratégicas de eliminação da hanseníase, filariose, esquistossomose e oncocercose como problema de saúde pública, tracoma como causa de cegueira e controle das geohelmintíases: plano de ação 2011 - 2015. Brasília: Ministério da Saúde; 2012.

26. Casavechia MTG, Melo GAN, Fernandes ACBS, Castro KR, Pedroso RB, Santos TS, Teixeira JJV. Systematic review and meta-analysis on Schistosoma mansoni infection prevalence, and associated risk factors in Brazil. Parasitology. 2018; 145(8):1000-14.

27. Gazzinelli MF, Gazzinelli A, Santos RV, Gonçalves LAO. A interdição da doença: uma construção cultural da esquistossomose em área endêmica, Minas Gerais, Brasil. Cad. Saúde Pública. 2002; 18(6):1629-38.

28. Facchini LA, Nunes BP, Felisberto E, Silva JAM, Silva Junior JB, Tomasi E. Assessment of a Brazilian public policy intervention to address schistosomiasis in Pernambuco state: the SANAR program, 2011-2014. BMC Public Health. 2018; 18(1):1200.

Correspondência para/ Reprint request to:

Jordana Herzog Siqueira

Universidade Federal do Espirito Santo,

Programa de Pós-Graduação em Saúde Coletiva,

Av. Marechal Campos, 1468,

Maruipe, Vitória/ES, Brasil

CEP: 29040-090

Tel.: (27) 99814-9525

E-mail:jordana.herzog@gmail.com

Submetido em: $31 / 10 / 2018$

Aceito em: 12/03/2019 